\title{
A comparative study of functional assays for tissue factor pathway inhibitor using normal plasma and clinical samples
}

\author{
M. J. Adams and R. Oostryck \\ (Received 30 September 1999; revised 1 February 2000; accepted 7 February 2000)
}

\begin{abstract}
Tissue factor pathway inhibitor (TFPI) is a Kunitz-type inhibitor that regulates the initiation of tissue factor-mediated coagulation. Recent reports in the literature have described variable results using different methodologies for TFPI measurement. In this study, we used one clotting and two amidolytic methodologies to assess TFPI functional levels. The study groups included normal healthy donors as well as patients with acute hepatitis, diabetes, coronary artery bypass graft operations, deep vein thrombosis, and prior to and during heparin therapy. The aims were to compare the results obtained in normal plasma using different assay systems, to compare TFPI levels in a range of clinical samples, including those previously not determined using a clotting methodology, and to report TFPI levels in patient groups previously not investigated. The results clearly demonstrate poor correlation between functional TFPI values using the different methodologies, highlighting the requirement for standardization. Blood Coagul Fibrinolysis 11:327-333 (C) 2000 Lippincott Williams \& Wilkins.
\end{abstract}

Keywords: tissue factor pathway inhibitor, functional assay, thrombosis

\section{Introduction}

There are reports in the literature of poor correlation between results obtained using different methodologies for tissue factor pathway inhibitor (TFPI) measurement. These have included discrepancies between functional and antigenic methodologies [1-3], as well as variable results using the clotting and amidolytic methodologies [4-6]. However, there are no reports that have used functional methods to directly compare levels of TFPI in normal plasma and clinical samples.

It was therefore the aim of this study to evaluate different functional methodologies for TFPI measurement to determine TFPI levels in both normal plasma and in plasma samples from clinical groups. Two amidolytic assays and a clotting endpoint methodology were established. The clinical groups included patients with acute hepatitis, diabetics, patients who had undergone coronary artery bypass graft operations (postCABG), patients with deep vein thrombosis (DVT), and a group of patients prior to and during heparin therapy.

\section{Materials and methods}

Purified factor VII (FVII) and factor X (FX) were purchased from Sigma Chemical Company (St. Louis, Missouri, USA). The recombinant tissue factor (TF) Innovin ${ }^{\circledR}$ was obtained from Baxter Diagnostics (Deerfield, Illinois, USA). Prothrombinex ${ }^{\circledR}$ was supplied courtesy of the Australian Red Cross (WA Branch) Blood Transfusion Service (Perth, WA, Australia). Normal serum albumin was purchased from the Commonwealth Serum Laboratories (Melbourne, Victoria, Australia). A selected synthetic peptide substrate (S-2222) was purchased from Chromogenix (Molndal, Sweden). Microtitre trays specific

The authors are with the School of Biomedical Sciences, Curtin University of Technology, Perth, Australia. Address correspondence to: $R$. Oostryck, School of Biomedical Sciences, Curtin University of Technology, GPO Box U 1987, Perth 6845, Australia. Tel: (+61) 89266 7518; fax: (+61) 89266 2342; e-mail: ioostryc@info.curtin.edu.au 
for glycoproteins were obtained from Nunc (Maxisorp, number 442404; Melbourne, Victoria, Australia). The glucose hectokinase kit for the determination of glucose was purchased from Boehringer Mannheim Systems (Castle Hill, NSW, Australia).

\section{Collection of samples}

Citrated plasma was obtained by drawing nine parts whole blood into one part $0.109 \mathrm{~mol} / \mathrm{l}$ sodium citrate, and centrifuging at $1200 \times g$ at $4^{\circ} \mathrm{C}$ for 10 min. Plasma was collected and then centrifuged again at $3000 \times g$ at $4^{\circ} \mathrm{C}$ for $20 \mathrm{~min}$. Reference plasma was pooled from 20 healthy donors and designated as containing $1 \mathrm{U} / \mathrm{ml}$ TFPI in the test systems used. All normal and clinical plasmas were stored at $-70^{\circ} \mathrm{C}$ prior to testing.

Patients included into the acute hepatitis group were not receiving anticoagulant therapy. Samples from postCABG patients were less than $48 \mathrm{~h}$ postoperation and were receiving therapeutic doses of unfractionated heparin. Patients with DVT were undergoing a therapeutic regime of unfractionated heparin. Diabetic patients were characterized by markedly elevated serum glucose and were not receiving anticoagulant therapy. Plasma was also obtained from patients with miscellaneous clinical problems during heparin anticoagulant therapy. $\mathrm{Pa}-$ tients with DVT were excluded from this group.

\section{Preparation of human brain thromboplastin}

Human brain tissue factor was prepared essentially by the method of Hjort [7].

\section{Coagulation screening tests}

International Normalised Ratio (INR) and activated partial thromboplastin time (aPTT) screening were performed using an automated coagulation analyser (Electra ${ }^{\mathbb{B}}$ MLA-1000) to determine clotting times. Tests were performed in duplicate.

\section{Amidolytic assays}

A 'fluid assay' and a 'binding assay' were performed as described previously [8]. For the fluid assay, a reaction mixture was initially prepared using equal volumes of TF (neat), FVII $(0.033 \mathrm{U} / \mathrm{ml})$, FX $(0.025 \mathrm{U} / \mathrm{ml})$ and calcium chloride $(0.025 \mathrm{~mol} / \mathrm{l})$, incubated at room temperature for $30 \mathrm{~min}$, then stored at $-70^{\circ} \mathrm{C}$ until required. To the wells of microtitre trays, $50 \mu \mathrm{l}$ plasma and $50 \mu \mathrm{l}$ aliquots of reaction mixture were added. After incubation for $10 \mathrm{~min}$ at $37^{\circ} \mathrm{C}, 50 \mu \mathrm{l} \mathrm{FX}(0.4 \mathrm{U} / \mathrm{ml})$ and S-2222 $(2.7 \mathrm{mmol} / \mathrm{l})$ were added and incubated for $25 \mathrm{~min}$ at $37^{\circ} \mathrm{C}$. To terminate the reaction, $50 \mu \mathrm{l}$ of $50 \%$ acetic acid was added and the absorbance read at $405 \mathrm{~nm}$ on a Titertek ${ }^{\circledR}$ Multiskan microtitre tray reader.

The binding assay was performed by initially incubating $100 \mu \mathrm{l} \mathrm{TF}$ (neat) overnight at $4^{\circ} \mathrm{C}$ in the wells of microtitre trays. After washing with Trisbuffered saline (containing $0.01 \mathrm{~mol} / \mathrm{l}$ Tris, $0.125 \mathrm{~mol} / \mathrm{l} \mathrm{CaCl} 2,0.15 \mathrm{~mol} / \mathrm{l} \mathrm{NaCl}, 0.05 \%$ sodium azide and $0.1 \%$ normal serum albumin; $\mathrm{pH} 7.3$ ), $50 \mu \mathrm{l}$ prothrombinex (containing $1 \mathrm{U} / \mathrm{ml} \mathrm{FX}$ and trace amounts of FVII) was incubated at $37^{\circ} \mathrm{C}$ for $1 \mathrm{~h}$. Following further washing, $50 \mu \mathrm{l}$ plasma was added and incubated at $37^{\circ} \mathrm{C}$ for $15 \mathrm{~min}$. The samples were again washed, followed by the addition of $50 \mu \mathrm{l} \mathrm{S}-2222(2.7 \mathrm{mmol} / \mathrm{l})$. After $30 \mathrm{~min}$ incubation at $37^{\circ} \mathrm{C}$, the reaction was stopped with the addition of $50 \mu \mathrm{l}$ of $50 \%$ acetic acid, and the absorbance read at $405 \mathrm{~nm}$ using the microtitre tray reader.

\section{TFPI coagulation inbibition time}

The TFPI coagulation inhibition time (TCIT) reaction mixture consisted of $50 \mu \mathrm{l}$ diluted human tissue factor $[1 / 4000$ dilution in TBS buffer $(0.05 \mathrm{~mol} / 1$ Tris, $0.15 \mathrm{~mol} / 1 \mathrm{NaCl}$; $\mathrm{pH} 7.2)$ ], $50 \mu$ l test plasma and $50 \mu \mathrm{l}$ reference plasma. The test plasma was heat precipitated at $56^{\circ} \mathrm{C}$ for $15 \mathrm{~min}$ to remove fibrinogen and other coagulation factor activity. The TCIT reaction mixture was incubated at $37^{\circ} \mathrm{C}$ for $3 \mathrm{~min}$. One hundred microlitres of $0.025 \mathrm{~mol} / \mathrm{l} \mathrm{CaCl}_{2}$ was then added to initiate coagulation and the clotting time recorded using the Coag-a-Mate ${ }^{\circledR}$ XM Analyser (Organon Teknika, Boxtel, The Netherlands).

Each TFPI assay was optimized for reagent activity using normal plasma.

\section{Glucose assessment in diabetic patients}

Assessment of glucose levels in plasma from diabetic patients was performed using the Hitachi Boehringer Mannheim 917 Automated Analyser. Glucose levels were determined using a commercial glucose hectokinase colourimetric/enzymatic method (Boehringer Mannheim Systems).

\section{Statistical analysis}

Paired Student's $t$ tests were performed to compare the means of sets of data. $P<0.05$ was considered statistically significant.

\section{Results}

Normal and clinical samples were screened using an INR and aPTT. Glucose levels were determined in diabetic patients. A summary of the data is presented in Table 1. 
Table 1 Summary of average data for normal and clinical samples

\begin{tabular}{lccccc}
\hline Sample & $n$ & $\begin{array}{c}\text { Age } \\
\text { (years) }\end{array}$ & INR & $\begin{array}{c}\text { aPTT } \\
(\mathrm{s})\end{array}$ & $\begin{array}{c}\text { Glucose } \\
(\mathrm{mmol} / \mathrm{l})\end{array}$ \\
\hline Normal & 20 & 23.0 & 1.10 & 30.1 & \\
Hepatitis & 6 & 48.8 & 1.07 & 28.8 & \\
Diabetes & 24 & 58.8 & 1.23 & 32.9 & 15.9 \\
PostCABG & 18 & 70.1 & 1.38 & 44.2 & \\
DVT & 18 & 48.8 & 1.90 & 63.4 & \\
Preheparin & 16 & 62.2 & 1.24 & 32.4 & \\
Postheparin & 16 & 62.2 & 1.28 & 70.2 & \\
\hline
\end{tabular}

INR, International Normalised Ratio; aPTT, activated partial thromboplastin time; CABG, coronary artery bypass graft; DVT, deep vein thrombosis.

Normal and clinical samples were assessed for functional TFPI using the fluid assay, binding assay and TCIT. A summary of the data is presented in Table 2. There were no statistically significant differences between the mean TFPI in normal plasma obtained using the three TFPI methodologies $(P<0.05)$. Across all three assays, there were statistically significant differences in the mean TFPI between normal plasma and hepatitis patients $(P=0.0446)$, diabetics $(P=0.0002)$, postCABG patients $(P=0.0002)$, patients with DVT $(P=0.0001)$, preheparin plasma $(P=0.026)$ and postheparin plasma $(P=0.0001)$. There were statistically significant differences between the mean TFPI in diabetic patients using the fluid and binding assays $(P=0.0008)$, and the binding assay and TCIT $(P=0.0342)$. There were statistically significant differences between the mean TFPI in DVT patients using the binding assay and TCIT $(P=0.0342)$. There were statistically significant differences between the mean TFPI in postheparin plasma using the fluid and binding assays $(P=0.0005)$, fluid assay and TCIT $(P=0.0213)$, and the binding assay and TCIT $(P=0.0034)$. There were statistically significant differences between the mean TFPI in pre- and post-heparin using the fluid and binding assays $(P=0.0001)$, fluid assay and TCIT $(P=0.001)$, and the binding assay and TCIT $(P=0.041)$. There were no other statistically significant differences between the mean TFPI in patient groups using the three TFPI methodologies $(P>0.05)$ (Table 2$)$.

Table 3 summarizes the correlation coefficients for data obtained using the three functional TFPI assays in assessing the groups of normal and clinical samples. The average correlation across all samples was 0.44 using the fluid assay and binding assay, 0.48 between the fluid assay and TCIT, and 0.35 between the binding assay and TCIT. There were statistically significant differences between the results for all normal and clinical samples using the fluid and binding assays $(P=0.0001)$, and binding assay and TCIT $(P=0.0001)$. There was no statistically significant difference between the mean TFPI in all normal and clinical samples using the fluid assay and TCIT $(P=0.1946)$.

\section{Discussion}

There was no significant difference between the mean TFPI in normal plasma obtained using each

Table 2. Summary of tissue factor pathway inhibitor (TFPI) data in normal and clinical samples using the fluid assay, binding assay and TFPI coagulation inhibition time (TCIT)

\begin{tabular}{|c|c|c|c|c|c|c|c|c|c|}
\hline \multirow[b]{2}{*}{ Sample } & \multicolumn{3}{|c|}{ Fluid assay } & \multicolumn{3}{|c|}{ Binding assay } & \multicolumn{3}{|c|}{ TCIT } \\
\hline & Mean & $\mathrm{SD}$ & Range & Mean & $\mathrm{SD}$ & Range & Mean & $\mathrm{SD}$ & Range \\
\hline Normal & 1.11 & 0.36 & $0.52-1.86$ & 1.11 & 0.29 & $0.53-1.57$ & 1.12 & 0.34 & $0.57-1.66$ \\
\hline Hepatitis & 0.94 & 0.46 & $0.54-1.65$ & 0.84 & 0.21 & $0.62-1.07$ & 0.87 & 0.13 & $0.72-1.04$ \\
\hline Diabetes & 1.00 & 0.33 & $0.57-1.72$ & 0.83 & 0.21 & $0.53-1.54$ & 0.99 & 0.34 & $0.51-1.84$ \\
\hline PostCABG & 0.91 & 0.33 & $0.46-1.40$ & 0.80 & 0.15 & $0.51-1.09$ & 0.88 & 0.36 & $0.52-1.91$ \\
\hline DVT & 0.78 & 0.26 & $0.35-1.40$ & 0.74 & 0.15 & $0.48-0.95$ & 0.90 & 0.34 & $0.31-1.40$ \\
\hline Preheparin & 1.05 & 0.39 & $0.50-1.95$ & 0.82 & 0.17 & $0.54-1.15$ & 1.06 & 0.39 & $0.55-1.69$ \\
\hline Postheparin & 2.35 & 1.09 & $1.05-4.70$ & 1.14 & 0.13 & $0.78-1.34$ & 1.68 & 0.67 & $0.89-3.20$ \\
\hline
\end{tabular}

Mean, standard deviation (SD) and range of TFPI values are expressed in U/ml.

CABG, coronary artery bypass graft; DVT, deep vein thrombosis. 
Table 3. Summary of correlation coefficients obtained from data using fluid assay, binding assay and tissue factor pathway inhibitor (TFPI) coagulation inhibition time (TCIT), for TFPI

\begin{tabular}{lccc}
\hline Sample & $\begin{array}{c}\text { Fluid assay/ } \\
\text { binding assay }\end{array}$ & $\begin{array}{c}\text { Fluid assay/ } \\
\text { TCIT }\end{array}$ & $\begin{array}{c}\text { Binding assay/ } \\
\text { TCIT }\end{array}$ \\
\hline Normal & 0.18 & 0.26 & 0.08 \\
Hepatitis & 0.41 & 0.81 & 0.14 \\
Diabetes & 0.62 & 0.40 & 0.25 \\
PostCABG & 0.48 & 0.23 & 0.10 \\
DVT & 0.33 & 0.09 & 0.20 \\
Preheparin & 0.54 & 0.29 & 0.20 \\
Postheparin & 0.03 & 0.38 & 0.44 \\
Average correlation & 0.44 & 0.48 & 0.35 \\
$P$ value & 0.0001 & 0.1946 & 0.0001 \\
\hline
\end{tabular}

With the exception of the $P$ values, results are expressed as a correlation coefficient. $P<0.05$ considered statistically significant. CABG, coronary artery bypass graft; DVT, deep vein thrombosis.

assay system. The mean TFPI obtained using the fluid $(1.11 \mathrm{U} / \mathrm{ml})$ and binding $(1.11 \mathrm{U} / \mathrm{ml})$ assays in the assessment of 20 normal plasma samples was higher than other reports in the literature [9-13]. The higher TFPI reported in this study may be due to the number of samples used and individual plasma variation. There are no detailed reports in the literature that describe functional levels of TFPI in normal plasma using a clotting methodology. The normal TFPI range taken across the three TFPI assays was $0.52-1.86 \mathrm{U} / \mathrm{ml}$. This range of functional TFPI values is similar to other studies [8-14].

The mean TFPI in six patients with acute hepatitis was lower in comparison with normal plasma. There are no previous reports of functional TFPI levels in patients with acute hepatitis, although normal levels have been reported in patients with other liver disorders. These include hepatocellular disease $[9,15]$, acute and chronic liver disease $[9,16]$ and decompensated cirrhosis [17]. Increased levels of functional TFPI have previously been reported in patients with chronic liver disease [13]. The degradation and clearance of TFPI is controlled to a significant extent by the liver [18]. There is no evidence from the study presented here that altered function of the liver, due to acute hepatitis, contributed toward increased functional levels of TFPI in the plasma of these patients. Indeed, the lower TFPI values reported here could possibly be due to increased clearance, utilization or consumption of the inhibitor associated with inflammatory processes.

The mean level of functional TFPI in diabetic patients reported in this study was similar to a previous report [13]. The results in the 24 diabetic patients in this study were within the usually accepted normal range. Interestingly, the mean level for TFPI in diabetic plasma was significantly reduced in comparison with the mean level in normal plasma samples. The significant reduction in functional TFPI in the diabetic group is largely due to values obtained using the binding assay, which may reflect different forms of TFPI or other unknown influences.

Diabetics, particularly those in which the disease is severe, frequently present with thrombotic problems as well as hypercholesterolaemia. The group of patients in this study had a marked increase in mean glucose concentration, demonstrating poor control of glucose levels, and normal plasma TFPI levels as measured in the fluid assay and TCIT. However, the low result for the binding assay suggests altered TFPI functional availability. It is possible altered lipoprotein profiles interfere with TFPI function as assayed in the binding methodology. Studies are continuing to elucidate this phenomenon.

Patients who underwent CABG operations demonstrated a significant reduction in the mean level of functional TFPI after surgery when compared with normal patients. It has previously been reported that TFPI levels are reduced during and after operative procedures [19]. All patients in this study received unfractionated heparin postoperatively. An increase in TFPI in the postCABG patients was therefore expected. The slight decrease in functional TFPI using all three assays in these patients does not correlate to expected results. Decreased levels of TFPI during surgery may indicate significant consumption of the inhibitor or may reflect a physiological response to underregulate $\mathrm{TF}$-mediated coagulation. 
Significantly decreased levels of functional TFPI were demonstrated in this study in patients with DVT in comparison with normal plasma. Functional levels of TFPI in patients with DVT have been reported to be within the normal range [15]. The reduced levels were especially demonstrable using the binding assay. The decreased TFPI levels reported in this study may indicate consumption of TFPI, a mild deficiency of the inhibitor or reduced availability of TFPI in patients within this group. Decreased levels of TFPI may therefore contribute toward the thrombotic tendencies seen in these patients.

An average 1.8-fold increase in functional TFPI was observed in 16 patients after heparin administration using all three assay systems. The postheparin effect of TFPI was therefore demonstrated using each assay system in this study. The level of functional TFPI observed during heparin therapy in the patients in this study was slightly lower than peak levels in comparison with other reports [2022]. This is likely to be due to the small increase in TFPI as measured in the binding assay. This ratio was 1.39 , compared with 2.24 using the fluid assay, and 1.58 using the TCIT. These variations in results may be due to the different forms of TFPI released from the endothelium and whether these are detected using the TFPI methodologies in this study.

There were statistically significant differences between the mean TFPI in diabetics, patients with DVT and postheparin treatment using different assay methodologies. The functional TFPI in the same plasma samples using different assay systems clearly demonstrate poor correlation between results. There was poor correlation between all assays when comparing individual samples. The highest correlation across all samples was using the fluid assay and the TCIT $(r=0.48)$. The correlation between results using the fluid assay and binding assay $(r=0.44)$, and the binding and TCIT $(r=0.35)$ also indicated that there was poor interassay reproducibility. The results of this study clearly demonstrate the poor inter-assay reproducibility between functional TFPI assays. Similar findings have been reported in which large discrepancies existed between TFPI results using a clotting assay and a synthetic peptide substrate assay [4-6].

The poor correlation between the results obtained using the three functional assays could have two explanations. The functional activity of TFPI in an individual plasma may be due to the different forms of TFPI present in the sample. Alternatively, the individual mechanisms of the functional TFPI assay systems used in this study may detect only specific forms of TFPI. The functional assays used in this study were selected as they may more closely reflect the in vivo processes of the inhibition of TFmediated coagulation. These assay systems determine functional TFPI based on the ability of the inhibitor to bind to TF-FVIIa in the presence of activated FX. In particular, the binding assay consistently demonstrated lower results in comparison with the other TFPI methodologies, in all patient groups.

The three functional TFPI assays used in this clinical study may detect different forms of the inhibitor. In plasma, TFPI is present as a full-length molecule, as well as truncated, lipoprotein-associated, lipoprotein-free and endothelial-associated forms. The precise role that each of these forms of TFPI has in the regulation of TF-mediated coagulation is not clearly understood. The detection of each of these different forms of TFPI using functional methodologies has also not been characterized.

It is speculated that the different forms of TFPI present in plasma, lipoprotein associated, truncated and free, may be detected to varying degrees in current functional TFPI methodologies. These forms of TFPI may therefore contribute to the low correlation in the same plasma samples using these assays. Another explanation is that the different form(s) of TFPI present in plasma may be dependent on the clinical situation of the patient. It is well documented that patients undergoing heparin therapy have marked increases in functional TFPI due to the release of the inhibitor from the endothelium. It has been demonstrated in this study that functional TFPI levels were increased using the three TFPI assay systems. The degree of increase was different as determined by the three methodologies in this study, and this may be due to the varying ability of the TFPI assays to detect endothelialreleased TFPI.

Another explanation for the poor correlation between functional TFPI assays could be due to the mechanisms within each assay. Although the synthetic peptide substrate assays and TCIT each measured the functional activity of TFPI in a plasma sample, the latter did not have long incubation periods. This implied that the TCIT was more dependent on the initial rate kinetics of the inhibition by TFPI, and therefore may not reflect the total inhibitory capacity of TFPI in the sample [23]. This may account for the poor correlation between assays. Additionally, as TF-mediated coagulation occurs within seconds in vivo, the anticoagulant ability of TFPI reflected in the TCIT is more likely to reflect in vivo conditions [21].

Blood Coagulation and Fibrinolysis 2000, Vol 11, No 4 
The mechanisms of the binding assay may also contribute to the poor reproducibility between TFPI methodologies. This assay is dependent on the binding of TF and phospholipids to a surface prior to the addition of FVII, FX and a source of TFPI. The consistently lower results that were demonstrated using the binding assay, in comparison with the fluid assay, may be due to the structural arrangement of phospholipids with TF. The binding of activated FVII and activated FX, and therefore TFPI, may be affected, resulting in the detection of lower amounts of TFPI in this assay system.

The ability of TFPI to inhibit clotting in vivo is likely to be due to the free form of the inhibitor present in plasma [24], or by TFPI associated with platelets near the site of vessel injury. It is tempting to suggest the measurement of the free form of TFPI in a plasma sample would therefore be of most significance. The major problem in determining functional levels of free TFPI is that this form of the inhibitor is a minor component of total TFPI. The sensitivity of current methodologies do not accurately quantitate free TFPI. Future work must focus on isolating the different forms of TFPI, investigation of the inhibitory role of the different forms of the inhibitor and the determination of the particular forms of TFPI that are measured in currently available functional TFPI methods. This will lead to standardization of these assays.

\section{Acknowledgements}

The authors wish to thank Dr Ross Baker, Mr Jim Thom and the Coagulation Unit in the Department of Haematology at Royal Perth Hospital for access to patient samples and routine screening of these samples, and the staff and student volunteers from Curtin University for donation of normal plasma samples for use in this study.

\section{References}

1. Hubbard AR, Weller LJ, Gray E. Measurement of tissue factor pathway inhibitor in normal and postheparin plasma. Blood Coal Fibrinol 1994; 5: 819-823.

2. Jeske W, Hoppensteadt D, Fareed J, Barnes E. Measurement of functional and immunologic levels of tissue factor pathway inhibitor. Some methodologic considerations. Blood Coag Fibrinol 1995; 6: S73-S80.

3. Bognacki J, Hammelburger J. Functional and immunologic methods for the measurement of human tissue factor pathway inhibitor. Blood Coag Fibrinol 1995; 6: S65-S72.

4. Lindahl AK, Jacobsen PBJ, Sandset PM, Abildgaard U. Separation of tissue factor pathway inhibitor by heparin affinity: plasma from cancer patients and post- heparin plasma contain increased amounts of fraction with high anticoagulant activity. Blood Coal Fibrinol 1991; 2: 713-721.

5. Lindahl AK, Abildgaard U, Larsen ML, Staalesen R, Hammer AKG, Sandset PM, et al. Extrinsic pathway inhibitor (EPI) released to the blood by heparin is a more powerful coagulation inhibitor than is recombinant EPI. Thromb Res 1991; 62: 607-614.

6. Wun TC, Huang MD, Kretzmer KK, Palmier MO, Day KC, Bulock JW, et al. Immunoaffinity purification and characterisation of lipoprotein associated coagulation inhibitors from Hep G2 hepatoma, change liver and SK hepatoma cells. J Biol Chem 1990; 265: 16096-16101.

7. Hjort PF. Intermediate reactions in the coagulation of blood with tissue thromboplastin. Scand J Clin Lab Invest 1957; 9: 1-182.

8. Adams MJ, Dunstan RA, Oostryck R. Interference by lupus anticoagulant in a functional assay for tissue factor pathway inhibitor. Thromb Res 1995; 80: 435440.

9. Warr TA, Rao LVM, Rapaport SI. Human plasma extrinsic pathway inhibitor activity: II plasma levels in disseminated intravascular coagulation and hepatocellular disease. Blood 1989; 74: 994-998.

10. Warr TA, Warn-Cramer BJ, Rao LVM, Rapaport SI. Human plasma extrinsic pathway inhibitor activity: I. standardisation of assay and evaluation of physiologic variables. Blood 1989; 74: 201-206.

11. Sandset PM, Larsen ML, Abildgaard U, Lindahl AK, Ødegaard OR. Chromogenic substrate assay of extrinsic pathway inhibitor (EPI): levels in the normal population and relation to cholesterol. Blood Coag Fibrinol 1991; 2: 425-433.

12. Adams MJ, Dunstan RA, Oostryck R. Comparison of two functional assays for tissue factor pathway inhibitor. In: Proceedings of the 28th Annual Scientific Meeting of the Haematology Society of Australia; Perth, Australia, 19-22 September 1994.

13. Berrettini M, Malaspina M, Parise P, Lucarelli G, Kisiel W, Nenci GG. A simple chromogenic substrate assay of tissue factor pathway inhibitor activity in plasma and serum. Am J Clin Pathol 1995; 103: $391-$ 395.

14. Rapaport SI. Inhibition of factor VIIa/tissue factorinduced blood coagulation: with particular emphasis upon a factor Xa-dependent inhibitory mechanism. Blood 1989; 73: 359-365.

15. Bajaj MS, Rana SV, Wysolmerski RB, Bajaj SB. Inhibition of the FVIIa-tissue complex is reduced in patients with disseminated intravascular coagulation but not in patients with severe hepatocellular disease. J Clin Invest 1987; 79: 1874-1878.

16. Sandset PM, Abildgaard U, Larsen ML. Heparin induces release of extrinsic coagulation pathway inhibitor (EPI). Thromb Res 1988; 50: 803-813.

17. Andersson TR, Bell H, Sandset PM, Ødegaard OR, Aamodt LM. New coagulation inhibitor levels in pneumonia, disseminated intravascular coagulation and liver disease (Abstract). Thromb Haemost 1987; 58: 305A.

18. Warshawsky I, Broze GJ, Schwartz AL. The low density lipoprotein receptor-related protein mediates the cellular degradation of tissue factor pathway 
inhibitor. Proc Natl Acad Sci USA 1994; 91: 66646668.

19. Sandset PM, Høgevold HE, Lyberg T, Andersson TR, Abildgaard U. Extrinsic pathway inhibitor in elective surgery: a comparison with other coagulation inhibitors. Thromb Haemost 1989; 62: 856-860.

20. Lindahl AK, Abildgaard U, Stokke G. Extrinsic pathway inhibitor after heparin injection: increased response in cancer patients. Thromb Res 1990; 59: 651656.

21. Lindahl AK, Sandset PM, Abildgaard U. The present status of tissue factor pathway inhibitor. Blood Coag Fibrinol 1992; 3: 439-449.
22. Østergaard P, Nørdfang O, Petersen LC, Valentin S, Kristensen, H. Is tissue factor pathway inhibitor involved in the antithrombotic effect of heparins? Haemostasis 1993; 23: 107-111.

23. Hansen JB, Huseby KR, Huseby NE, Ezban M, Nordøy A. Tissue factor pathway inhibitor in complex with low density lipoprotein isolated from human plasma does not possess anticoagulant function in tissue factor induced coagulation in vitro. Thromb Res 1997; 5: 413-425.

24. Rapaport SI, Rao LVM. Initiation and regulation of tissue factor-dependent blood coagulation. Arterioscler Thromb 1992; 12: 1111-1121. 